\title{
Educación Superior Intercultural en disputa. Trayectorias de la Universidad Intercultural Amawtay Wasi
}

\author{
Paola A. Vargas Moreno \\ Pontificia Universidad Católica del Ecuador, Quito, Ecuador. \\ Email:paolakahlo@gmail.com
}

\begin{abstract}
Resumen: ${ }^{1}$ El presente documento describe y analiza cuáles son y cómo se transforman las relaciones entre el Estado ecuatoriano -haciendo énfasis en el gobierno de Rafael Correa- y la Universidad Intercultural Amawtay Wasi (UIAW), como institución articulada a la organización social indígena, a propósito de la configuración de la educación superior intercultural y la construcción de la interculturalidad como discurso político y programa operativo en Ecuador. A través de una descripción del proyecto epistemológico y político de la UIAW, y la realización de una cronología de las relaciones cambiantes entre el Estado y la UIAW, el artículo da cuenta de cómo se ha construido un campo político en Ecuador que hace imposible la interculturalidad como universalidad dialogada hoy.

Palabras clave: Interculturalidad, educación superior, participación política, Política dual, Movimiento Indígena, Estado.
\end{abstract}

\section{Intercultural Higher Education in dispute. Paths of the Amawtay Wasi Intercultural University}

\begin{abstract}
This paper describes and analyzes which are they, and how are transformed, the relationships between the State of Ecuador -emphasizing the government of Rafael Correa- and the Intercultural University Wasi Amawtay (UIAW), as institution articulated to indigenous social organization, regarding the setting up of intercultural higher education and the construction of interculturality as political discourse and operational program in Ecuador. Through a description of the epistemological and political project of UIAW, and clarifying a timeline of the changing relationships between the state and the UIAW, the article states how a political field has been built in Ecuador that makes impossible interculturality as dialoging universality today.
\end{abstract}

Key words: Interculturalism, higher education, political participation, dual Policy, Indigenous Movement, State.

\section{Ensino Superior Intercultural em disputa. Trajetórias da Universidade Intercultural Amawtay Wasi}

Resumo: Este artigo descreve e analisa quais são e como se transformam as relações entre o Estado equatoriano, ressaltando o vinculo entre o governo de Rafael 
Correa e a Universidade Intercultural Amawtay Wasi (UIAW), como instituição articulada à organização social indígena, a proposito da configuração do ensino superior interculturais e a construção do interculturalidade como discurso político e programa operacional no Equador. Por meio de uma descrição do projeto epistemológico e político da UIAW e a realização de uma cronologia das mudanças nas relações entre o Estado e a UIAW, o artigo pretende dar conta de como no Equador tem-se construído um campo político que torna impossível a interculturalidade como universalidade dialogada nos dias de hoje.

Palavras-chave: Interculturalidade, Ensino superior, Participação política, Política dual, Movimento Indígena, Estado.

$* * / *$

\section{Introducción}

Las relaciones dinámicas entre Movimiento Indígena y Estado en el Ecuador han permitido la construcción hegemónica del devenir socio-político nacional. Los contenidos y programas del proyecto educativo son parte significativa de esta construcción. En un principio, la Educación Intercultural Bilingüe (EIB), como logro del Movimiento Indígena, daba cuenta de una co-construcción dialogada entre las necesidades de las comunidades, constituidas en demandas organizadas, y la implementación de una política de incorporación corporativa por parte del gobierno como componente del proyecto de Estado-nación; la EIB se constituía como la materialización de una efectiva política dual ${ }^{2}$ que articulaba movilización contenciosa y participación en el Estado. No obstante, estos procesos de diálogo y negociación, asentados en las prácticas de gobierno desde la década de los ochenta y empleados de manera efectiva por las organizaciones indígenas, se han ido transformando de manera aguda y evidente durante el período de gobierno de Rafael Correa (2006-2014), período caracterizado por el debilitamiento del Movimiento Indígena y el refortalecimiento del Estado.

Durante esta última década, con gran fuerza en el ámbito educativo institucional, lentamente y de manera compleja, se ha ido consolidando un discurso a favor de la interculturalidad como derrotero ideal para tramitar las diferencias étnico-culturales del territorio ecuatoriano; no obstante, el discurso de la interculturalidad ha encontrado múltiples trabas para poder consolidarse como realidad en las prácticas institucionales, tanto del proyecto educativo indígena en el ámbito de la educación superior, como del proyecto de gobierno materializado en los procesos de evaluación y acreditación de las instituciones de educación superior y la construcción de criterios de interculturalidad. Así, hasta el momento, la interculturalidad se ha constituido en una promesa incumplida.

En este marco, el presente documento describe y analiza cuáles son y cómo se transforman las relaciones entre el Estado ecuatoriano, haciendo énfasis en el gobierno de R. Correa, y la Universidad Intercultural Amawtay 
Wasi (UIAW), como institución articulada a la organización social indígena, a propósito de la configuración de la educación superior intercultural y la construcción de la interculturalidad como discurso político y programa operativo en Ecuador.

Para ello son necesarios tres momentos:

En primera instancia, se presenta una descripción general del proyecto epistemológico y político de la UIAW con el fin de explicar sus propuestas teóricas y aportes respecto al deber ser de la interculturalidad y de la educación superior en marcos de emancipación y decolonialidad.

En un segundo momento se realiza un recorrido cronológico que permite rastrear los encuentros entre los diferentes gobiernos de turno y la UIAW, etapas suscritas a los procesos de institucionalización, consolidación, evaluación estatal y cierre de la Universidad, desde su concepción hasta el año 2013. A partir de esta cronología será posible entender, de un lado, cómo se tramitan las negociaciones entre la UIAW y los gobiernos para dar forma a la agenda pública sobre educación superior intercultural en una constante correlación de fuerzas y, de otro, cómo se ha venido configurando un nuevo "campo de batalla" con el ascenso del gobierno de Correa.

Para finalizar, se explica cómo la actual configuración del campo de disputa por el proyecto de educación superior intercultural impide el cumplimiento de la promesa epistémica y el mandato constitucional de la interculturalidad como una universalidad dialogada tras la permanencia de un modelo particular de desarrollo y la consolidación de un renovado sujeto de derechos más cercanos al multiculturalismo neoliberal que a una alternativa emancipatoria para dar trato justo y consensuado a la diferencia étnica-cultural a nivel nacional.

Si bien el documento resalta el potencial político y epistemológico del proyecto de la UIAW y denuncia las trabas institucionales y políticas interpuestas por el Estado ecuatoriano (con mayor fuerza en el período de gobierno de Correa); su objetivo final no es hablar en términos dicotómicos que enfrentan organización social indígena vs. Estado como si estas fueran posiciones ontológicas y estáticas. De manera crítica, la intención es mostrar las relaciones dinámicas, flexibles y contingentes (por ende diversas y cambiantes en el tiempo) que permiten que la educación superior intercultural como institución y la interculturalidad como proyecto, estén hoy en la arena pública como escenario de disputa. La Universidad Intercultural Amawtay Wasi se constituye así en la mejor excusa y el mejor ejemplo para dar cuenta de estas relaciones, siendo posible demostrar cómo las formas e intensidades de la pugna actual por la participación en el Estado y, por ende, por dar contenido a los proyectos que definen el devenir político, económico y social del país, en este caso en el ámbito de la educación superior intercultural, da cuenta, por una parte, del fortalecimiento acelerado del Estado y, en consecuencia, de la imposibilidad y falta de voluntad del Estado para reconocerse incompleto y dejarse abierto para negociar (puesto 
que lo que se negocia es el poder); mientras que, por otra parte, expone las limitantes del Movimiento Indígena para entrar a jugar en las arenas del Estado y conservar su legitimidad en este.

A la par, las reflexiones aquí expuestas contribuyen al análisis de las formas en las que el actual gobierno ha trasformado las condiciones de participación e inclusión del sujeto indígena en la toma de decisiones sobre el devenir nacional, siendo posible señalar el déficit que se instituye con el gobierno de Correa en el ámbito de la participación política de la sociedad civil organizada, situación preocupante y para tener en cuenta en aras de pensar nuevas formas de organización social y nuevos ejercicios para incidir efectivamente en el sistema político nacional.

\section{Educación Superior Intercultural: Universalidad dialogada vs. Universalidad universalizante (Perspectiva de análisis)}

La idea, única de Occidente, de un conocimiento único y universal en aras de una verdad única y universal, requeriría de una institución, igualmente, única y con pretensiones de universalidad. Esta institución será la universidad (Santos 1998, 2007). Los sistemas educativos y las políticas educativas que lo soportan, fungen como patrón para encaminar a las sociedades hacia un modelo particular de desarrollo, funcionan como dispositivo para administrar la diferencia socio-cultural de un territorio específico y, por ende, construyen un modelo adecuado de sujeto político (sujeto de derechos).

Desde la década de los setenta, ante la aceleración de las reformas producto del neoliberalismo de una parte, y el posicionamiento de las demandas por reconocimiento y redistribución de las organizaciones sociales de otra, los clásicos objetivos de la universidad como institución moderna fueron cediendo espacio tanto al mercado como a la sociedad civil para ingresar a los escenarios de diseño y construcción de la educación superior. La crisis de la universidad tradicional se va haciendo evidente y proyectos tanto de carácter mercantil (al servicio del mercado) como de carácter alternativo (al servicio de las demandas de las organizaciones sociales) van surgiendo y tomando fuerza. Para el caso latinoamericano, en lo que respecta a los proyectos diseñados desde las organizaciones sociales, es preciso anotar que dichas apuestas serán de marcado carácter étnico-cultural y reclamarán como suyo el campo universitario como escenario legítimo para el ejercicio de derechos de reconocimiento, justicia social, valoración de conocimientos propios y formación de cuadros políticos.

En este marco, durante las últimas tres décadas la categoría “interculturalidad” ha sido bandera clave para dotar de carácter decolonial y esperanza de emancipación a las nuevas apuestas educativas en pos de un nuevo proceso que promete una ruptura con las prácticas de la educación superior tradicional, prácticas que han perpetuado la desigualdad y la 
exclusión social, sobre todo hacia algunos sectores específicos de la población como lo son los pueblos y nacionalidades indígenas, afrodescendientes y campesinos.

Lentamente, dos propuestas se enfrentan y sus tensiones van logrando presencia en la escena pública regional: por un lado, se ha fortalecido un proyecto de universidad universalizante que re-produce y legitima un conocimiento científico y una verdad única, en donde el diálogo con saberes y sujetos "no modernos" es imposibilitado y lo particular/local es dejado como ejemplo o campo de experimentación y no como lugar de producción de subjetividades y conocimientos; este modelo se ha erigido históricamente en pro de una visión desarrollista del progreso que acompasa el triunfo del capitalismo y ve en la diferencia un potencial mercado (sujetos materia prima - sujetos consumidores). De otro lado, se va levantado, entre intelectuales de izquierda y organizaciones sociales indígenas, un proyecto de universidad dialogada basado en un discurso en pro de un nuevo modelo de desarrollo en respeto y armonía con la naturaleza, una nueva forma de entender y construir la diferencia en base al diálogo, el respeto y la conciencia de la exclusión colonial histórica, y una manera renovada de articular lo particular con lo universal. Hoy, para el caso ecuatoriano, ambas propuestas de universidad llevan por nombre educación superior intercultural.

Dos proyectos de educación superior se han enarbolado en el discurso y se confrontan en escenarios de toma de decisión con el fin de dar contenidos teóricos y directrices operativas a la universidad deseada para el Ecuador. Definir qué es y cómo se logra el "buen vivir” como renovado paradigma de desarrollo, situar el lugar del indígena y de lo indígena como forma de administrar la diferencia bajo la categoría interculturalidad y establecer cuál es el sujeto de derechos (tanto en el acceso a los servicios sociales como en la participación en la toma de decisiones del devenir nacional), son tres tareas que hoy concentran la atención tanto de los intelectuales y técnicos vinculados al Estado, como de los intelectuales y políticos que hoy se agrupan en diferente facciones de un Movimiento Indígena en transformación.

En el discurso, muchas veces pareciera que "buen vivir”-“sumak kawsay", "diálogo de saberes”-“interculturalidad” y "derechos ciudadanos”-“derechos colectivos”, fueran categorías sobre entendidas por todos gracias a los aires de la época y a la fuerza de la repetición en las diversas esferas públicas; no obstante, los proyectos y agendas programáticas que cada uno de los sectores en el escenario de disputa le dan a una u otra categoría, develan muchas veces que los discursos se distancian de las prácticas y se quedan en promesas incumplidas. Se constituyen discursos emblemáticos de carácter general-generalizante que resultan en prácticas diversas y, muchas veces, contradictorias.

La movilidad de las fronteras en los discursos y la flexibilidad de las prácticas de alianza y distanciamiento entre las diferentes instancias (de un lado, del Estado y sus gobiernos de turno, y del otro, del Movimiento 
Indígena, las organizaciones indígenas y la UIAW), es un asunto que se hace evidente cuando se realiza un análisis de larga duración y a múltiples escalas que tiene en cuenta las experiencias locales y las estrategias internacionales como marcos que construyen los discursos y las prácticas a nivel nacional en una permanente correlación de fuerzas; es decir, solo un análisis que exponga las diferencias, las similitudes, los límites y las articulaciones entre lo local, lo nacional y lo internacional, tanto al hablar de la estructura de gobierno como de la estructura organizativa del Movimiento Indígena y la UIAW, permite explicar la complejidad de las relaciones (desencuentros - acercamientos, rupturas - negociaciones) entre los actores en disputa. Así, lo que en ocasiones no funcionó a nivel nacional, funcionó a nivel local, se catapultó con triunfo a nivel internacional, o viceversa; al parecer, la oposición radical es solo una certeza en el discurso oficial de la esfera pública, pero en las prácticas cotidianas se mantienen relaciones móviles como perpetuación del ejercicio de política dual en los intersticios.

Esto implica reconocer que, como algunas dependencias del Estado bien han sabido leer el contexto socio-político presente y levantan sus agendas de acción en base a esta lectura, también el Movimiento Indígena y la UIAW, leyendo de una manera oportuna el marco de oportunidades políticas que se abre o se cierra, tanto a escala local como nacional e internacional, ha decidido actuar en uno u otro nivel, con una u otra entidad del Estado o con alguna organización u entidad que les permita alianzas estratégicas para enfrentarse al reto de demandar participación ante el Estado.

Este es el contexto en el que se han suscrito las relaciones entre el Estado y la organización social indígena durante las últimas décadas y, en consecuencia, en dónde se tejen las negociaciones que han posibilitado el surgimiento e institucionalización de la UIAW y su posterior evaluación y clausura de parte del Estado. Este es el complejo prisma que permite encuadrar una mirada crítica frente a la experiencia de la UIAW.

\section{Universidad Intercultural Amawtay Wasi}

La Universidad Intercultural Amawtay Wasi, tiene como tarea fundamental responder desde la epistemología, la política y la ética a la descolonización de conocimiento, debe constituirse en un espacio de reflexión, que proponga nuevas formas de concebir la construcción del conocimiento considerando que las nacionalidades y pueblos tiene sus propios saberes y que la responsabilidad de los hombres y mujeres comprometidos con esta tarea es investigar, revalorizar y potenciar los saberes locales y deconstruir las ciencias del conocimiento, como requisito indispensable para trabajar no desde las respuestas de orden colonial epistemológico, filosófico, ético, político y económico; sino desde la propuesta construi- 
da sobre la base de los principio filosóficos que se anuncian.

Universidad Intercultural Amawtay Wasi (2004).

Frente a la colonialidad como legado del proceso de modernización al que han sido sometidas las periferias del sistema mundo, la UIAW nace como una propuesta alternativa en educación superior que mantiene como base filosófica y conceptual la "racionalidad Abya Yala" que articula lo organizativo, lo simbólico, lo integral, lo complejo y lo milenario, a través de cuatro principios: la relacionalidad, la dualidad complementaria, lo vivencialsimbólico y la reciprocidad. Su misión, objetivos y preceptos metodológicos se fundan en estos principios, mientras que sus acciones y reflexiones referentes al espacio y el tiempo mantienen cronologías y disposiciones sujetas a la relación cosmológica andina del eterno tiempo en espiral. Su propuesta pedagógica, al igual que su malla curricular, se organizan en base a la cruz cuadrada o chakana (UIAW 2004) (Sarango 2008).

Los componentes epistemológicos de su estructura emergen de cinco elementos específicos que articulan el esquema estructural de la propuesta y conforman los cinco Centros de Saber en los cuales se divide la currícula en particular y el proyecto de educación superior en general. Los componentes son: el yachay (saber) que emergiendo en el norte como aire, da razón del conocer, el interpretar, el manejar una epistemología particular; el munay (amar) que a la izquierda se sitúa en forma de agua para dar lugar a la pasión, la intuición, el deseo, la capacidad de pensar con el corazón; el ruray (hacer) que brota del sur como tierra para hablar de la capacidad de vivenciar, de construir, de producir, de formar y autoformarse, de realizar y materializar, de promover y experimentar; el ushuay (poder) que llega complementario hecho fuego como energía y potencia que dinamiza; y, por último y como eje articulador central, el kawsay (origen-vida), sabiduría transversal que hace referencia a la vida como experiencia plena, como tensión perenne entre las polaridades armónicas, posibilidad real de la interculturalidad (UIAW 2004) (Sarango 2008).

La batalla por resistir/re-existir se hace material en la creación de la Universidad como estrategia que canaliza y coloca en el debate científicosocial contemporáneo las intenciones de posesionar como ciencia los saberes ancestrales andinos, más allá de minimizar sus potencialidades cerrando su radio de acción e influencia a la sierra y selva ecuatorianas y mucho más allá de incluirse como empresa educativa en proceso de mercantilización. Si bien es complicada (y para algunos incluso inadecuada) la idea de accionar dentro de los marcos legales del sistema de educación y, juzgando superficialmente, se podría afirmar que es descabellado escoger y asumir como agente de cambio a una de las instituciones modernas heraldo de la Modernidad, la universidad; la certeza de emplear la educación como un instrumento eficaz para la decolonización y el coraje de emprender nuevos rumbos en la encrucijada diseños globales-historias locales, permite subrayar como deber comunitario el compartir con la intención de crear un nuevo desarrollo integral para toda la humanidad, un buen 
vivir justo, armónico, digno y transformativo que promueva el equilibrio en todos los niveles de vida del ser humano y el mundo, material y espiritual, que lo circunda (UIAW 2004) (Bustamante y Vargas 2010).

La construcción de estas nuevas formas de desarrollo que, por fuera del capitalismo, promueven formas comunitarias y solidarias de producción, acumulación y redistribución en armonía con la naturaleza, pasa necesariamente por la construcción de una sociedad en donde las diferencias sean respetadas en marcos de igualdad, justicia y dignidad, una sociedad que, teniendo en cuenta las grandes brechas históricas que separan a los habitantes de un mismo territorio y la heterogeneidad constitutiva de los mismos, opte por establecer diálogos horizontales para tomar las decisiones que definirán su devenir político, económico y socio-cultural. Esta sociedad, para el Movimiento Indígena y, como resultado, para la UIAW, debe ser una sociedad intercultural.

La interculturalidad se hace un eje transversal de la propuesta de la UIAW. El currículo intercultural, como propuesta para operativizar la interculturalidad en el ámbito académico, centra su atención en el problema del conocimiento: ¿Cómo se produce el conocimiento?, ¿quién lo produce?, ¿quién lo legitima?, ¿cómo recuperar y validar los saberes propios? Para dar luces a este dilema que se enmarca en el problema mismo de la colonialidad (del saber, del ser y del poder) ${ }^{3}$ se propone un diálogo de saberes que parte de darle un mismo estatus de valor, importancia y legitimidad a los conocimientos científicos-occidentales y a los saberes no científicos-no occidentales. Así, las mallas curriculares de cada una de las trazas impartidas inician con un semestre o tronco común en donde se plantea la propuesta epistemológica y la apuesta política del proyecto en general (semestre 0), continúan con un primer ciclo de formación en ciencias ancestrales, un segundo ciclo en ciencias occidentales y, finalmente, un tercer ciclo de formación con énfasis en la interculturalidad (UIAW 2004) (Bustamante y Vargas 2010).

El camino del conocimiento intercultural considera tres grandes ciclos: el Runa Yachay o ciclo de formación con énfasis en las ciencias ancestrales, el Shuktak Yachay o ciclo de formación con énfasis en las ciencias occidentales y el Yachay Pura o ciclo de formación con énfasis en la interculturalidad [...] Estos tres ciclos comprenden cuatro niveles de aprendizaje: el Aprender a Pensar Haciendo Comunitariamente, el Aprender a Aprender, el Aprender a Desaprender y Reaprender y, por último, el Aprender a Emprender [... El El proceso de aprendizaje está orientado al desarrollo y formación de sujetos prácticos reflexivos e intuitivos, de sabios más que profesionales [...] Este camino va acompañado de un recorrido que se inicia con la interdisciplina y concluye con la transdiciplina en los niveles superiores de aprendizaje (UIAW 2004: 10).

A esta propuesta teórica que apuesta por un diálogo de saberes horizontal entre culturas diferentes tras reconocer la diferencia epistémica 
jerarquizada como una forma de dominación colonial y, aun así, mantener la esperanza en la búsqueda de un bienestar común para la humanidad, la denominaré interculturalidad como universalidad dialogada. Esta propuesta parte de requerir como condición necesaria, antes del establecimiento de acuerdos, el reconocimiento de un carácter de incompletitud ${ }^{4}$ tanto en el colectivo como en el individuo, conocer en su complejidad al otro y, en consecuencia, establecer canales de comunicación y negociación que implican confianza recíproca dependiendo de las capacidades, las experiencias y las potencialidades; solidaridad para compartir conocimientos, estrategias, recursos y agendas; y, en consecuencia, voluntad para distribuir el poder de decisión en las manos de los que participan en el diálogo. Esta comprensión del deber ser de la interculturalidad propone un diálogo más allá de la cultura, un diálogo que implique negociar las formas de lo político, lo económico y lo social a nivel local y nacional, en consecuencia, negociar las agendas públicas de inserción y participación política, los modelos de desarrollo económico más adecuados para la sociedad en su heterogeneidad y las estrategias para promover la justicia y la dignidad social. Promisoriamente, aquí se enclava el discurso de la UIAW.

Desde principios de la década de los noventa, la DINEIB y la CONAIE iniciaron trabajos conjuntos para proponer un sistema alternativo de educación integral (básica, secundaria y superior), con un currículo que recogiera planteamientos urgentes de las comunidades y las organizaciones indígenas: la participación directa de la población indígena tanto en el sistema educativo local como en el sistema político nacional, la incorporación de prácticas de producción y organización tradicionales vigentes en las comunidades indígenas, la introducción de formas propias y ancestrales de conocimiento, la recuperación de la lengua y la historia del pueblo indígena y su participación en la historia nacional y regional, la incorporación de maestros y sabios de las comunidades, la lucha por el reconocimiento de la diferencia y la redistribución de la riqueza, la construcción de una sociedad intercultural y el ejercicio de autodeterminación en el marco de un Estado plurinacional, entre otros.

Cada vez con mayor fuerza en el escenario público, tanto educativo como político, se hacía evidente la apuesta por construir un centro de estudios superiores desde y para las comunidades indígenas, situación que llevó a algunos líderes históricos del Movimiento Indígena, con apoyo de intelectuales ecuatorianos mestizos y miembros de instituciones vinculadas a redes de cooperación internacional preocupados por la situación indígena en América Latina, a promover una campaña para reflexionar sobre el estatus del conocimiento en relación a las tareas políticas y sociales de los movimientos indígenas. Su apelación a la decolonización de las ciencias iba más allá de la epistemología y se constituía en una tarea política de primera necesidad: la de crear y recrear, desde la epistemología, los marcos categoriales que posibilitaran una práctica política de emancipación y un proceso de autorreflexión sobre los contenidos que han sido impartidos en la educación tradicional y los que realmente son pertinentes y necesarios para las realidades indígenas, en particular, y ecuatorianas, en general. 
Como respuesta a esta campaña por inaugurar procesos en el ámbito de la educación superior, algunos sectores de la Dirección Nacional de Educación Intercultural Bilingüe (DINEIB) apoyaron convenios con universidades privadas (Universidad Católica y Universidad Politécnica Salesiana, por ejemplo) para abrir cursos, carreras o especializaciones con componentes de carácter indígena. Igualmente, algunas escuelas vinculadas a la DINEIB y otras constituidas con ayudas de misiones católicas y evangélicas, al igual que algunos líderes comunitarios apoyados por ONGs que venían trabajando en alternativas de formación técnica para capacitar a los indígenas que culminaban satisfactoriamente su educación básica y secundaria, fueron constituyendo instituciones de carácter técnico y tecnológico en los campos pedagógico y agropecuario. Mientras tanto, algunos sectores de la Confederación de las Nacionalidades Indígenas del Ecuador (CONAIE), con una intención política fundamentada en la autodeterminación, se preocuparon por dirigir su propuesta hacia la construcción de una universidad propia de carácter intercultural.

Dicha preocupación encuentra sus primeras líneas de resolución en 1996 con la llegada, por primera vez, de un diputado indígena al Congreso Nacional, a saber, Luís Macas (kichwa-saraguro) como representante y cabeza del recién conformado Movimiento de Unidad Plurinacional Pachakutik. Macas junto a Leónidas Iza (Diputado Provincial de Cotopaxi en aquel entonces), serán los encargados de promover el proyecto de ley para la creación de la Universidad Intercultural de las Nacionalidades y Pueblos Indígenas del Ecuador Amawtay Wasi (UINPI Amawtay Wasi) con el fin de complementar integralmente la apuesta por una educación indígena a nivel superior, recogiendo la sabiduría originaria de las nacionalidades indígenas para cumplir un papel revitalizador de las propuestas políticas y culturales de las comunidades. Esta empresa liderada por la CONAIE y el Pachakutik logra, a paso lentos, avances en el ámbito político institucional con impactos importantes en el ámbito educativo; se hace posible el reconocimiento de las derechos colectivos de los pueblos indígenas en la Constitución de 1998, la inclusión de la población indígena en la Ley de Educación superior de 2000 y la consolidación del proyecto de creación de la Universidad Intercultural Amawtay Wasi mediante Ley 2004 - 40 del 5 de agosto del 2004, publicada en Registro Oficial No. 393 (Macas 2005) (Dávalos 2005).

La UIAW es una propuesta de educación superior construida desde el Movimiento Indígena que mantiene como principales promotores y respaldos a la CONAIE y el Instituto Científico de Culturas Indígenas (ICCI). La UIAW, es el resultado de un largo proceso de trabajo, debate y sistematización en la que participó un equipo interdisciplinario conformado por directivos, docentes, investigadores y profesionales indígenas y no indígenas, nacionales y extranjeros.

La UIAW cuenta con tres carreras o trazas aprobadas en 2003 y abiertas en el transcurso del 2007 y 2008; a saber:

- Ingeniería agroecológica con clases y talleres de preparación de 
tesis en las chakras ${ }^{5}$ de Conocoto (Quito D.M., Pichincha) y La Esperanza (Pedro Moncayo, Pichincha), aunque inició labores en Cayambe, igualmente, en la Provincia de Pichincha.

- Arquitectura con mención en arquitectura andina en la chakra de Conocoto; $y$,

- Licenciatura en ciencias de la educación con mención en pedagogía intercultural en la chakra de San Pablo de Tenta (Saraguro, Provincia de Loja) y en la Provincia de Morona Santiago (inicialmente en Macas, capital de la Provincia y, en la actualidad, en el aja Chiguaza, cantón Huamboya).

Paralelamente, ha adelantado procesos de educación informal a través de Comunidades de Aprendizaje, cursos de capacitación y formación técnica desarrollados en diversos territorios del país con colaboración técnica y financiera de entidades de cooperación internacional, ONGs nacionales e internacionales, y estamentos del gobierno ecuatoriano. Durante el 2013, al margen de la legalidad, hacían trámites para abrir una nueva traza en Comunicación Intercultural.

Durante el 2008, en colaboración con la Universidad Central de Ecuador, se desarrollaba el Diplomado Superior en Investigación Intercultural donde se formaban quienes serían lo futuros docentes de la UIAW y se construían los módulos y contenidos curriculares de las diferentes trazas (UIAW 2004).

La UIAW es miembro de la Red de Universidades Indígenas, Interculturales y Comunitarias de Abya Yala RUIICAY, conformada por siete instituciones de educación superior intercultural de la región ubicadas en México, Colombia, Venezuela, Bolivia y Nicaragua, país sede central. Con financiación del Fondo Indígena y cooperación alemana (GTZ) en el marco del proyecto Universidad Indígena Intercultural (UII), en sociedad con la Universidad Autónoma Indígena Intercultural de Cauca, Colombia (UAIIN) y la Universidad de las Regiones Autónomas de la Costa Caribe Nicaragüense (URACCAN), durante el 2008 y el 2009 la UIAW desarrolló la Maestría en Gestión del Desarrollo con Identidad para el Buen Vivir Comunitario de carácter semipresencial e itinerante (con clases en Conocoto y Cauca).

El financiamiento de la institución, conforme a su estatuto orgánico, corresponde a un modelo de autofinanciación. En ocasiones obtuvo apoyos puntuales de entidades estatales como el Consejo de Desarrollo de las Nacionalidades y Pueblos del Ecuador (CODENPE), recibió donaciones de instituciones no gubernamentales internacionales (de Bélgica, España, Inglaterra, Italia y Suiza) y nacionales, o ganó proyectos a ejecutar en el marco de la cooperación internacional (Sarango, 2008) (Mato, 2008). En la actualidad la mayoría de su financiación reside en los ingresos económicos propios de las matrículas que pagan los estudiantes vinculados a la institución. 
Si bien la Universidad tiene su sede administrativa en Quito, nunca ha impartido clases en la ciudad y, ajustándose a la legalidad, solo pudo iniciar clases en los territorios de las comunidades indígenas cinco años después de aprobada la resolución de fundación. En los territorios de las comunidades (con excepción de Conocoto en donde cuenta con una infraestructura adecuada y un porcentaje significativo de sus estudiantes no son indígenas), la institución no cuenta con instalaciones de su propiedad, siendo unidades educativas de inicial, básica y secundaria, salones comunales e inclusive emisoras comunitarias, los lugares para el desarrollo de encuentros y clases los fines de semana (Bustamante y Vargas, 2010).

Según datos del 2008, a la fecha se habían matriculado 90 estudiantes en las Comunidades de Aprendizaje y, en pregrado se habían matriculado 160 estudiantes en donde las mayorías eran hombres. En el curso de postgrado o Diplomado Superior en Investigación Intercultural que se inició en octubre de 2007, contaban con 31 estudiantes. La edad promedio de los estudiantes de Comunidades de Aprendizaje era de 30 años, mientras que la edad promedio de los estudiantes de pregrado era de 25 años y la del curso de diplomado superior fue de 40 años (Sarango 2008) Para el primer semestre del 2013 eran 70 los estudiantes registrados, la gran mayoría (80\%) cursaban últimos semestres o se encontraban preparando sus tesis.

\section{UIAW - Estado. Cronología de los encuentros}

Desde su origen como proyecto institucional de organizaciones indígenas y aliados académicos hasta su presente como institución clausurada debido al proceso de evaluación desfavorable adelantado en el marco de la Reforma Educativa, el Estado y la UIAW han establecido múltiples relaciones (encuentros y desencuentros) a propósito del carácter institucional de la Universidad, las formas de vinculación y participación recíprocas y, durante los últimos años, el contenido y proyecto de la categoría interculturalidad.

Tanto las posiciones en permanente guerra ${ }^{6}$ construidas en torno a uno u otro tema como las formas e intensidades que adquieren estas posiciones, son cambiantes en el tiempo, dependientes de situaciones contingentes amarradas a procesos históricos de larga data y resultado de un análisis del marco de oportunidades político en los ámbitos local, nacional e internacional. A continuación, se presenta una suerte de recorrido cronológico de los encuentros entre los diversos gobiernos nacionales, en representación del Estado, y la UIAW como aliada al Movimiento Indígena, trayectoria que permite señalar tanto los proyectos y las estrategias desplegadas por los actores como las formas en que estos encuentros-desencuentros van co-construyendo una narrativa particular respecto a la construcción de la interculturalidad en el marco de la educación superior. 


\section{.2003 - 2004: Institucionalización de la UIAW. Triunfo del Movimiento Indígena en el marco de una alianza fallida}

Tras una convulsa década que puso de manifiesto el debilitamiento de la estructura y la institucionalidad estatal y, a la par, posicionó al Movimiento Indígena como sujeto político en la esfera pública, los años 2003 y 2004 representaron el momento más álgido de las posibilidades de la organización indígena en la escena del poder institucional: la participación directa en las altas instancias del poder ejecutivo nacional y la transformación sustancial del Movimiento Indígena. Es en esta coyuntura en donde el proyecto por una educación superior intercultural movilizada por el Movimiento Indígena, el proyecto de la UIAW, logra su institucionalización legal frente al Estado.

El comienzo del siglo XXI será complejo para el Movimiento Indígena. Entre comunidades de base organizándose en torno a proyectos locales técnico - productivos, muchas veces promovidos por ONGs y financiados por organismos de cooperación internacional, y una dirigencia que decide participar en la arena política institucional gracias a procesos de autorreflexión interna y el reconocimiento de un marco de oportunidades político favorable que recogía los frutos de las movilizaciones y levantamientos que terminaron en derrocamientos presidenciales e implicaban una solidaridad nacional y una hegemonía en el ámbito de la lucha social; se consolida Pachakutik en el 2002 y, para el 2003, se establecía una alianza con el Partido Sociedad Patriótica, alianza que para el 2004 se había quedado solo en promesas electorales.

De forma paralela, con el ascenso de Luis Macas al Ministerio de Agricultura en el marco de la alianza, el proyecto de la UIAW identificaba la posibilidad de lograr institucionalidad con el Estado. Al igual que el ala del Movimiento Indígena que funda Pachakutik como respuesta a un marco de oportunidades favorable, un ala del Movimiento Indígena (aliada a la CONAIE y por lo tanto a Pachakutik y liderada por Luis Fernando Sarango, rector de la UIAW) ve en la alianza el marco oportuno para catapultar el proyecto legal de institucionalización de la Universidad e inicia labores para la aprobación. La tarea no fue fácil. Desde la redacción de la propuesta hasta las discusiones con los miembros del Consejo Nacional de Educación Superior (CONESUP), en donde se decidieron cosas no menores como el nombre de algunas trazas y el carácter privado de la Universidad, supuso el empleo de una estrategia más allá de la acción contenciosa y el uso a conveniencia de las redes creadas entre dirigentes indígenas y entidades del Estado en el marco de la alianza. Bien lo describe Luis Macas al hablar de la Ley de creación de la UIAW:

Yo creo que a nosotros más bien nos tocó armar otros mecanismo, incluso valernos del mismo lenguaje que se utiliza para hacer las políticas y para poder salir con nuestra propuesta. Más bien lo que hemos tenido que hacer es aprovechar los momentos y hubo un momento en que había bastante gente conocida que estaba dirigien- 
do el CONESUP, un buen amigo de la Provincia de Manabí era el Presidente del CONESUP, y fuimos y le presentamos la propuesta, la conoció todo el equipo de su gente, y nos dijo: bueno a ponerlo en la agenda. Parece que ahí hubo el lio de que la Universidad iba a salir como universidad pública y ese fue el problema; ni académico ni nada, lo que sucede es que de ese pastelito que ellos se dividían, se tenía que dividir más si entraba una nueva universidad pública, entonces ese era el pretexto y por eso no nos aprobaron estos señores. Un día estando ahí en la sala de reuniones nos dicen: ¿pero por qué más bien no hacen una universidad particular cofinanciada con el Estado?... y claro, nosotros bien ingenuos, nos fuimos, desbaratamos toda esa cosa de educación pública, nos metimos en otra cosa, hicimos todas las gestiones que había que hacer y regresamos. Y en una nueva sesión del CONESUP, un mismo señor de ellos saca la Constitución y nos dice: ah! pero es que ustedes ya no pueden, no podemos aprobar porque la Constitución dice de que ya no pueden aprobarse las universidades como particulares cofinanciadas por el Estado, solo como particulares y nos tocó irnos por lo privado, hasta que se aprobó en una reunión, que querían hacer medio clandestina, pero nos soplaron y llegamos y nos aprobaron (Entrevista. Julio de 2013).

Así, a pesar del fracaso de la alianza a nivel nacional (Sociedad Patriótica - Pachakutik), el capital político y social acumulado por la dirigencia del Movimiento aliada a la UIWA, permitió su institucionalización; los lazos a nivel personal/local posibilitaron el acceso a la negociación y sentaron entidades sub-nacionales del Estado y del Movimiento Indígena para dar vida legal a la universidad intercultural.

\section{4-2006: Consolidación institucional. Nuevos retos políticos, nuevas formas de movilización}

La aprobación legal de la UIAW implicó aceptar una serie de retos en los que la organización indígena, en general, y los sujetos vinculados a la nueva institución, en particular, no tenían mucha experiencia. Comprobar la capacidad de consolidación institucional (racionalidad interna), sería el nuevo condicionante resultado de la legalidad, condicionante que poco tenía que ver con los contenidos epistemológicos y pedagógicos de una alternativa intercultural en educación superior o con las necesidades educativas de los territorios en donde la Universidad pretendía iniciar clases de manera inmediata.

Así, mientras Lucio Gutiérrez era derrocado (2005) -ya no por el Movimiento Indígena pero si con estrategias contenciosas propias a su accionar de fin de siglo, aprehendidas como formas legítimas de acción política que construyeron el imaginario nacional de la protesta-, la UIAW aprendió a funcionar en clave de institución moderna con el fin de cumplir la legalidad, consolidar funciones en su centro administrativo (Quito) e iniciar los procesos de formación académica en los territorios de los pue- 
blos y nacionalidades. Al respecto es importante anotar que las autoridades de la institución nunca estuvieron plenamente conformes con esta situación: si bien se reconocía a Quito como el centro administrativo, la UIAW no hacía referencia a este centro como la "sede principal” en donde se impartirían clases. En rigor, la UIAW pretendía iniciar sus actividades en los territorios indígenas de Morona-Santiago, Loja y Cañar tras la aprobación legal de la Universidad; no obstante, al reconocer a Quito como sede principal, el CONESUP en cumplimiento de la Ley, insistió en que solo permitía abrir otras "sedes” o "extensiones" cinco años después (es decir, para el 2009), situación que implicó postergar el comienzo de las clases con comunidades en donde ya existían lazos y compromisos, tanto académicos como políticos, para iniciar los procesos. Es ya una idea generalizada entre los miembros de la UIAW hablar de este condicionamiento de la Ley como un "pedir permiso para entrar en la propia casa”.

Empero, mientras que a nivel local era imposible iniciar clases dentro de los parámetros legales vigentes y las bases del Movimiento reclamaban explicaciones a sus dirigentes por los resultados de la alianza, y a nivel nacional la Ley condicionaba una relación en donde las posibilidades de acción de la UIAW eran restringidas a sus capacidades administrativas, el gobierno de transición no prestaba algún tipo de interés a las instituciones encargadas de administrar lo indígena y ganaba amplia acogida el proyecto de Alianza País; a nivel internacional, los aprendizajes de la Universidad como institución, las alianzas con un sector de la academia que posicionaría el discurso decolonial en América Latina y las tendencias de la cooperación internacional, harían real la apertura de los primeros procesos de formación institucionales: durante el año 2006 se abren las 4 primeras Comunidades de Aprendizaje de la UIAW en Cayambe (Pichincha), Macas (Morona-Santiago), Colta y Riobamba (Chimborazo) financiadas por las entidades de cooperación internacional SWISSAID, CARE Internacional y HEIFER. En este mismo marco se gestó el Programa de liderazgo y gestión comunitaria de la Escuela de Formación Política y Liderazgo “Lázaro Condo” en asociación con la ECUARUNARI.

\section{7-2008: Esperanza. ¿Apertura de un nuevo marco de oportunidades favorable?}

Para mediados del año 2007, la traza de Ciencias de la educación con énfasis en pedagogía intercultural abre su proceso de convocatoria y admisión en San Pablo de Tenta (Saraguro) y Macas (Morona-Santiago); al finalizar el año, aproximadamente 80 estudiantes iniciaban sus procesos de formación en territorios indígenas. Durante el 2008 la traza de Agroecología hará lo suyo en Cayambe (Pichincha) junto con Arquitectura en Conocoto (Pichincha), trazas que registraban unos 40 estudiantes en total. Un clima de esperanza reinaba en la UIAW. La convocatoria en los pueblos y la apertura de las trazas en los territorios indígenas era un logro mayor; la sensación de acogida de parte de las comunidades vinculadas a la institución en las diferentes chakras era evidente pues, por ejemplo, participaban masivamente a las actividades de cierre de cursos y socialización de las 
muestras de resultado de los emprendimientos en un evento denominado "La fiesta de la cosecha" que se realizaba cerrando cada ciclo y hacían explícito su compromiso con el proceso (Bustamante y Vargas 2010).

Mientras tanto, Correa asumía el poder ascendiendo en prestigio y credibilidad de manera vertiginosa con un discurso que prometía la transformación radical frente a las viejas y caducas formas de gobernar, un nuevo escenario político en donde todos los sectores sociales, en especial aquellos que habían sido excluidos de los procesos históricos de redistribución de la riqueza y el poder, por fin iban a ser protagonistas del cambio y beneficiarios directos de un nuevo gobierno. Se conjuraba una revolución para todos, una revolución que atendería de manera preferente a los más pobres, y entre ellos, a los "pueblos ancestrales”", la Revolución Ciudadana se colocaba en marcha ${ }^{8}$. La promesa se materializó en un triunfo electoral sin precedentes y parecía cumplirse de manera pronta con la convocatoria a la Constituyente del 2008 en donde participaron amplios sectores de la población, entre ellos, las diferentes facciones del Movimiento Indígena. Los aportes de estas facciones y sus aliados lograron colocar en el escenario constitucional temas como los derechos colectivos, los derechos de la naturaleza y el buen vivir (sumak kawsay), igualmente, lograron definir el carácter plurinacional e intercultural del Estado ecuatoriano; la inclusión de estos términos en la Constitución aprobada por referéndum el 28 de septiembre de 2008, se ve desde entonces como una de las herramientas más importantes para la lucha indígena contemporánea y uno de los logros más relevantes del Movimiento Indígena en el ámbito de la participación. En palabras de Luis Macas: “La Constitución tenemos que tomarla como un instrumento de lucha porque nos va a permitir mantenernos en la disputa. Es resultado de lucha de amplios sectores sociales y no un favor que nos ha dado el señor Correa voluntariamente” (Entrevista. Julio de 2013).

En este contexto, si bien la dirigencia y algunos estudiantes de la UIAW, afirman que las relaciones entre el gobierno y la Universidad siempre han sido distantes o inexistentes, como lo recalca Gerardo Simbaña, Coordinador Académico de la institución, "Relación nunca hubo desde el momento de la creación de la Amawtay Wasi que se creó como una universidad particular o privada, desde ese momento el Estado se desentendió. No es que actualmente las relaciones están mal, nunca hubo relación” (Entrevista. Junio de 2013); el ascenso de Correa representó la promesa de un nuevo marco de oportunidades favorable para la sociedad civil en general, y el Movimiento Indígena no fue ajeno a este llamado, por ende la UIAW también estuvo atenta a las posibilidades de acción en este particular momento.

Así, para la segunda mitad del 2008 se firma el acuerdo de colaboración institucional entre la UIAW y la Dirección Nacional de Salud de los Pueblos Indígenas del Ministerio de Salud Pública del Ecuador para ejecutar el proyecto "Sensibilización en Salud y Medicina Intercultural. Sumak kausay pachakutin - El retorno al bien vivir” que permitió la formación de 
127 Emprendedores en Gestión del Equilibrio Dinámico y Medicina Intercultural, todos funcionarios de la DNSPI de las provincias con mayor presencia de población indígena, entre ellos 7 funcionarios del Ministerio Nacional.

En esta instancia, un nuevo Estado en construcción, para lograr consolidarse, abre sus puertas a la negociación y llama a diferentes sectores de la sociedad civil que llegan con las apuestas más robustecidas que tenían. La interculturalidad y la plurinacionalidad son esas apuestas para el caso del Movimiento Indígena y, al lograr instituirlas en el aparataje constitucional, inician un proceso para hacer de estas ya no solo demandas particulares sino proyectos nacionales; la interculturalidad y la plurinacionalidad entran en el debate de la esfera pública para lograr hegemonía. No obstante, las circunstancias de la negociación van cambiando y las capacidades de la cuota indígena en el poder y sus aliados se colocan a prueba, al igual que las capacidades de la UIAW.

\section{9-2013: Configuración de un nuevo campo de batalla. Transformaciones en las condiciones de la negociación}

De verdad que hace falta un diálogo sincero que nos conduzca a un acuerdo amplio como sujetos individuales y colectivos de derechos. Así, podríamos opinar, aportar y quizá ser parte del proceso revolucionario que se dice está en marcha, no como objetos sino como sujetos revolucionarios, cumpliendo tareas concretas en varios frentes o actividades, no como simples consumidores de migajas y favores políticos. Luis Fernando Sarango (2009).

Durante el proceso constituyente hay un proceso cercano entre el Movimiento y el Estado que se fue haciendo distante, en donde se perdió la agenda programática. Las relaciones en un momento de negociación se pierden en dos años y ante la preocupación de cualquier forma de oposición que mantenían salidas a través de grandes movilizaciones, el gobierno comienza con un discurso para combatir disque lógicas corporativas a través de la cooptación, la promoción de divisiones internas o la criminalización para generar miedo. Luis Andrango (Entrevista. Abril de 2013).

En el proceso de refortalecimiento del Estado, asuntos antes olvidados por el gobierno se vuelven una preocupación urgente. En una primera etapa de gobierno (2007-2010) fue evidente la apuesta encaminada hacia una re-construcción de la infraestructura vial del territorio ecuatoriano posicionada en los medios como "revolución vial"; en una segunda etapa (2010-hoy), la transformación estructural promovida se concentra en el ámbito 
de la educación. Estamos frente a un proceso de "revolución educativa" que mantuvo rápido trámite en los niveles básico y secundario y hoy se manifiesta convulsa en el nivel superior. Ambas, tanto la "revolución vial" como la "revolución educativa”, se enmarcan en los nuevos parámetros construidos desde el Plan Nacional de Desarrollo "Plan Nacional para el Buen Vivir. Construyendo un Estado Plurinacional e Intercultural”. Así, el sumak kawsay, la plurinacionalidad y la interculturalidad también se consolidan como preocupaciones urgentes en nuevos escenarios de disputa por la hegemonía entre el Estado y las organizaciones sociales, entre ellas, el fragmentado y en transformación Movimiento Indígena; estas preocupaciones sirven como contexto legal y operativo desde donde se piensa hoy la educación superior.

El “nuevo" desarrollo propuesto desde el gobierno, ahora con apellidos socialista e indigenista, sigue manteniendo la falacia desarrollista de la Modernidad pues si bien, por un lado, promete cambiar la matriz productiva transformando los modos de producción, acumulación y redistribución del capital, de otro lado se funda en las promesas incumplidas de la Modernidad: la igualdad, la libertad y la fraternidad, la novedad está en la adjetivación con tendencias de moda que fungen como nueva promesas a nivel local: la ciudadanía universal, la plurinacionalidad y la interculturalidad. En palabras de Dávalos:

Aquí se plantea una contradicción lógica de gobiernos que se dicen socialistas o que adscriben de alguna manera a las tesis de la izquierda política, pero que se dirimen, se estructuran, y a la larga definen la correlación de fuerzas en las luchas del poder al interior de las coordenadas del liberalismo y de sus instituciones. Es decir, es el liberalismo el que establece el marco general en el cual situar las respuestas antisistema y antiliberal de los discursos legitimantes de estos gobiernos, lo que por definición es un contrasentido, porque si el discurso es socialista y si con ese discurso se ganan las elecciones, lo menos que deberían hacer es construir una mínima institucionalidad política que de alguna manera se relacione con el proyecto socialista, algo que ningún gobierno que se dice socialista lo ha hecho hasta el momento (Dávalos 2010: 275).

En rigor, es preciso no olvidar que el socialismo es uno de los grandes meta relatos modernos y que la promesa de ascenso de Correa es la "Revolución Ciudadana”, eslogan que bien podría cumplirse bajo parámetros políticos de corte liberal y republicano. Algunos apuntes en este sentido señalaba la UIAW en su Boletín Digital en el 2010:

La “revolución ciudadana” carece de fundamento teórico y viabilidad alguna, pues no puede haber "revolución” desde los escritorios, amparada en una maquinaria propagandística sin límites y carente de participación social. En contextos de una realidad intercultural y plurinacional aunque con inequidad, hablar de “ciudadanía” al clásico estilo liberal, es retrógrado por decir lo menos (Sarango. 2010 Agosto). 
El “nuevo” modelo de desarrollo de la Revolución Ciudadana es la renovación de la apuesta por el dominio integral de la naturaleza, es la puesta en marcha de la técnica sobre la naturaleza, es el fortalecerse internamente para incrustarse en la competencia del mercado global de una forma efectiva, todo bajo parámetros deseados de igualdad y justicia social. Como bien lo expone Dávalos:

Alianza País es la apuesta de las nuevas facciones de la burguesía, sobre todo aquellas vinculadas a la globalización del capital, por reformular los contenidos de la acumulación capitalista en el Ecuador hacia los polos de la minería en gran escala, la privatización territorial, los megaproyectos extractivos y los ejes multimodales (como aquellos de los megaproyectos IIRSA), la producción de agrocombustibles, la privatización de la renta petrolera, la mercantilización de la naturaleza por la vía de los servicios ambientales, la producción de transgénicos, entre otros (Dávalos s/f, s/r).

En este contexto, la interculturalidad aparece así como estrategia de inclusión que garantizará el cumplimiento de los mentados deseos. En teoría, centrando la atención en el ámbito de los discursos oficiales posicionados en la esfera pública, el proyecto es similar: un diálogo horizontal entre diferentes. No obstante, la realidad histórica y la voluntad política no alcanzan para cumplir la promesa.

El sistema universitario, y con este las instituciones de educación superior, la universidad para nuestro caso particular, se reestructura para dar paso y directrices de operativización a este renovado desarrollo:

Elevar la calidad y propender a la excelencia y pertinencia del sistema de educación superior ecuatoriano y articularlo con las necesidades de la transformación de las matrices productiva, energética, de conocimiento y de servicios para el Buen Vivir, así como a los procesos de participación social (Reglamento de Régimen Académico. De los fines. 2013)

Nuevas categorías se hacen paradigma: calidad, excelencia y pertinencia se instituyen como primer renglón del deber ser educativo, objetivos a lograr de manera imperativa, no negociable, y con parámetros construidos desde las instancias tecnocratizadas del gobierno y el Banco Interamericano de Desarrollo (BID) (Tünnerman 2001) (Dávalos 2010). La interculturalidad, en segundo renglón, queda como una posibilidad y no una condición:

El currículo debe incorporar criterios de interculturalidad en cada área del conocimiento, nivel de formación y área formativa. Esta incorporación se podrá realizar mediante: a.) La contextualización del aprendizaje, el reconocimiento de la diversidad cultural en la experiencia educativa y la referencia a conocimientos pertenecientes a diversas cosmovisiones y epistemologías o a miradas diferentes de 
otros grupos socioculturales (de género, grupos etarios, etnias y otros grupos culturales) en asignaturas y cursos, siempre que sea posible y pertinente y que exista un acervo intelectual organizado, práctico o teórico, que permita el diálogo de saberes, conocimientos y de servicios para el Buen Vivir, así como a los procesos de participación social (Reglamento de Régimen Ácadémico. De la Interculturalidad. 2013).

Así, la Revolución Ciudadana implica una transformación radical con los sujetos de derechos construidos por décadas entre las demandas, ofertas y negociaciones de las organizaciones sociales y el Estado. El ciudadano, individuo universal, es ahora el único legal sujeto de derechos; ya no lo serán más la organizaciones de la sociedad civil en auge en la década de los noventa, quienes demandaban de manera colectiva ante el Estado a través de sus representantes y lograban el reconocimiento de sus derechos de manera corporativa para redistribuirlos en sus colectividades, las mismas que lograron la incursión de categorías como “derechos colectivos”, “derechos de la naturaleza”, “plurinacionalidad” e “interculturalidad” en la Constitución vigente. Así, los procesos de incorporación de los "sujetos otros” al aparato del Estado en la actualidad, se realizan en calidad de individuos y no de representantes de colectividades.

Desde este nuevo contexto es posible afirmar que se diseña una interculturalidad entre individuos con diversas identidades culturales y no una interculturalidad entre culturas, en el amplio sentido de la palabra. La interculturalidad como eslogan y el trabajo de operativización adelantando en el ámbito educativo, evidencian la renovación de una estrategia ya empleada con éxito en toda América Latina durante la década de los noventa, el uso de un dispositivo para tramitar la diferencia anclado a las estrategias del multiculturalismo neoliberal/posneoliberal en donde el Estado se encarga de incluir las luchas por reconocimiento e identidad en la institucionalidad legislativa, olvidando las necesidades de redistribución tanto en lo económico como en lo político; más que querer hacer del indígena un ciudadano, crea un indígena-ciudadano que se circunscribe al proyecto Moderno-Colonial en su etapa neoliberal a través de "constitucionalismos multiculturales” y/o “ciudadanías multiculturales”.

A esta apuesta por un encuentro entre individuos diferentes, que no siempre implica diálogo o negociación entre los acervos socio-culturales de cada uno de ellos, olvidando el reconocimiento de la diferencia epistémica jerarquizada históricamente que no se repara con la sola visibilización del otro y que, aun así, promete la búsqueda de un bienestar común para la humanidad, la denominaré interculturalidad como universalidad universalizante. Esta propuesta parte de reconocerse lo suficientemente fuerte para suponerse completo (en los términos de Santos, 2012), para suponerse suturado y definirse como una totalidad constituida (en los términos de LaClau y Mouffe, 1987) ${ }^{9}$, tanto en el colectivo como en el individuo, olvidando prepotentemente la imposibilidad de esta condición. En esta perspectiva, no se propone entonces un conocer en su complejidad al 
otro y, en consecuencia, no requiere establecer canales de comunicación y negociación. La confianza recíproca en las capacidades, las experiencias y las potencialidades, se pierde antes de arribar al encuentro; la solidaridad para compartir estrategias, recursos y agendas, es un llamado que se olvida en el usufructo de los conocimientos del otro; y, en consecuencia, la voluntad para distribuir el poder de decisión, no se negocia. Esta comprensión del deber ser de la interculturalidad propone un "diálogo" centrado en el encuentro cultural, muchas veces esencialista, un relacionarse que no permite negociar las formas de lo político, lo económico y lo social, en consecuencia, no le interesa negociar las agendas públicas de inserción y participación política, los modelos de desarrollo económico más adecuados para la sociedad en su heterogeneidad y las estrategias para promover la justicia y la dignidad social. Lamentablemente, aquí se enclava el discurso del actual gobierno.

En este marco, desde el 2009 la UIAW hace parte de las instituciones de educación superior que están siendo evaluadas por el nuevo sistema de Evaluación, Acreditación y Aseguramiento de la Calidad del país y, si bien en antaño las dificultades referentes a la situación legal de la institución habían sido bastantes, a partir del 2009 se complejizan aún más pues el rasero de valoración del proyecto UIAW se ha ceñido a los parámetros universalistas de la educación superior clásica.

Frente a las prácticas y el accionar de la UIAW, de manera oficial, el Estado ecuatoriano se pronuncia en el 4 de noviembre de 2009 a través del "Informe de Evaluación de desempeño institucional de las universidades y escuelas politécnicas del Ecuador", realizado por el Consejo Nacional de Evaluación y Acreditación de la Educación superior (CONEA) en cumplimiento del Mandato Constituyente $\mathrm{N}^{\circ} 14$, documento con el cual se inicia un proceso de diseño y re-configuración del deber ser de la Educación Superior en Ecuador que se materializa con la creación de la Ley Orgánica de Educación superior (LOES) en el año 2010 -en un debate legislativo que duró aproximadamente un año y que gana la bancada presidencial por falta de una estrategia de participación clara, una oposición consolidada y fuerte $\mathrm{y}$, en últimas, por el Veto Presidencial ${ }^{10}$-.

Posteriormente, una vez cumplido el plazo legal de 18 meses para la evaluación de las instituciones de educación superior ubicadas en categoría “E”, entre ellas la UIAW, el 11 de abril de 2012 el nuevo organismo encargado resuelve ampliar 12 meses más la evaluación de la Universidad en particular al no ser tenidos en cuenta criterios de interculturalidad. Cumplidos los 12 meses, de manera tardía, se inauguraron procesos para discutir y coordinar la construcción de los criterios e interculturalidad que evaluaron a la Universidad. Para el 31 de octubre del 2013, la UIAW fue clausurada. Preguntas sobre la calidad de la participación en los escenarios de decisión, sobre los resultados de los procesos de decisión y sobre los intereses personales colocados en la mesa de decisión, aún quedan pendientes pues las formas en las que se participa hoy en la construcción de política pública hoy parecen pasar solo por una política de la asistencia y la 
evidencia (la firma y la foto) distanciándose cada vez más de una política de real influencia y decisión.

Los criterios estándar de evaluación, fueron adversos para la UIAW puesto que las prácticas, tanto educativas como administrativas de la Universidad, dan cuenta, de una parte, de las necesidades y posibilidades específicas y cotidianas de las comunidades donde trabaja la institución y estas se distancian significativamente de los diseños ideales propuestos por el Estado y, de otra, de las dificultades de la Universidad de funcionar en clave de institución moderna a pesar de nueve años de legalización como tal.

En cumplimiento de los requerimientos de la LOES 2010 y como parte del proceso de evaluación nacional en el que está inserto el sistema de educación superior y las instituciones de educación superior del Ecuador, el CONESUP y el ya referenciado CONEA fueron abolidos dándole paso a la constitución de tres nuevas entidades encargadas de la agenda política referente a la educación superior en Ecuador en donde el papel del Estado es determinante.

La LOES buscó poner fin a la colonización corporativa del Estado por parte de los elementos sujetos a la regulación pública. Retomando el espíritu fuertemente descorporativizador del proceso de transformación educativo, la LOES buscó evitar que los reguladores sean los regulados y el consecuente conflicto de intereses (CEAACES, 2012: 5).

Las tres nuevas entidades son la Secretaría Nacional de Educación superior, Ciencia, Tecnología e Innovación (SENESCYT) quien coordinará el proceso de reforma que será ejecutado por el Consejo de Educación superior (CES) y el Consejo de Evaluación, Acreditación y Aseguramiento de la Calidad de la Educación superior (CEAACES). Este último está a cargo, entre otras cosas, de "Aprobar la normativa para los procesos de evaluación, acreditación, clasificación académica y aseguramiento de la calidad de las instituciones del sistema de educación superior, programas y carreras, bajo sus distintas modalidades de estudio” (LOES Art. 174-b).

En este marco, el CEAACES mantiene 3 criterios pilares que funcionan como ejes de su política de evaluación: calidad, pertinencia y democratización; el CEAACES se crea para prevenir y contrarrestar

[...] el no cumplimiento de estándares mínimos de calidad, la falta de pertinencia de la oferta académica con las necesidades de desarrollo del país, y una óptica mercantil de la educación superior en detrimento de los derechos de los estudiantes, de los docentes y de la sociedad en su conjunto que acogió a los profesionales graduados en su seno (CEAACES, 2012:7-8).

Hasta ahora, en este particular contexto, los criterios para determinar 
qué se entiende por calidad educativa, pertinencia en pro del desarrollo del país e interculturalidad, entre otros, son parte de la agenda pública recuperada por el gobierno de Alianza País en la figura de sus funcionarios e intelectuales.

\section{Reflexiones finales}

La acción colectiva de las organizaciones indígenas en Ecuador y Latinoamérica ha posibilitado la complejización y ampliación de los discursos, los conceptos y las prácticas de los proyectos democracia y educación de formas inéditas cruzando las promesas incumplidas de la Modernidad con las necesidades locales cotidianas que se enfrentan al reto de renovar sus voces en los marcos de la política instituida. En este cruce de demandas y necesidades, gracias al ejercicio efectivo de una política dual que bien articuló acciones contenciosas y política de escritorio, lentamente y a pulso, el Movimiento Indígena logró colocar en las arenas de la política pública temas antes no pensados como el valor y la importancia de la diversidad cultural y, en consecuencia, la necesidad de establecer formas adecuadas para dar trámite justo y digno a la diferencia. En este marco se tejen los proyectos por una educación propia, por una educación para y desde el sujeto (político y epistémico) indígena.

Así, la comprensión de la emergencia de la interculturalidad como categoría a transversalizar en los múltiples espacios ya no solo del proyecto político de las organizaciones indígenas en transformación, sino también de un Estado en proceso de refortalecimiento institucional hoy, solo es posible tras el reconocimiento de la efectividad del accionar dual del Movimiento Indígena de antaño durante décadas. Si bien la representación corporativa que permitió la consolidación de este accionar nunca fue (y nunca será) la panacea, sí fue una estrategia útil que posibilitó la generación de un espacio de influencia para el sujeto indígena en los lugares de decisión del devenir socio-político nacional. En la actualidad, este espacio se ve realmente perdido.

$\mathrm{Al}$ entender las acciones de la UIAW como institución parte de las organizaciones articuladas al Movimiento Indígena en el ejercicio de una política dual, se puede situar el afán de la Universidad por lograr el reconocimiento de su proyecto de educación superior intercultural ante el Estado como una lucha legítima por querer influenciar e impactar el sistema político en aras de su reforma a través de la participación directa en las instancias estatales, para su caso, como parte del sistema de educación superior y protagonista de la consolidación de los criterios y estrategias que tranversalizarán la interculturalidad en el sistema.

Tanto la institucionalización de la UIAW en el 2004 como las tensiones producto del proceso de la evaluación de desempeño institucional iniciado por el CONEA en el 2009, el proceso de construcción de criterios para definir y regular la educación superior en el marco de la LOES y la clausura 
consecuente de la Universidad por parte del CEAACES, se comprenden entonces como la materialización de la disputa por la institucionalización del proyecto de educación superior intercultural en Ecuador en un ir y venir entre el accionar político institucional de la UIAW y la agencia del Estado. Empero, este ir y venir político ha tenido diferentes intensidades y fuerzas dependientes tanto de la organización interna de la UIAW como del proyecto de acción gubernamental, es decir, de una política de ordenación nacional cambiante.

La exacerbación de la heterogeneidad y fragmentariedad constitutiva del Movimiento Indígena (entre facciones, pero también entre bases y dirigentes) y la crisis de la representación concedida en antaño a organizaciones sociales y partidos políticos, fungen como contexto para el surgimiento y consolidación del actual proyecto de gobierno, proyecto que transforma la configuración del escenario político que había afianzado formas particulares y eficientes de negociación entre el Estado y las organizaciones sociales indígenas. De a pocos, el gobierno de Correa asciende con amplia aceptación tras la capitalización de discursos propios de la lucha indígena. A la par, se levanta un aire de conflicto que redunda en discursos de desconfianza y oposición radical. Curiosamente, los discursos de los ahora enemigos públicos levantaban la misma bandera: la interculturalidad. Se inaugura la disputa y los actores y sus agendas se reconfiguran.

En este marco, la configuración de un nuevo campo de batalla devela una red compleja de interacciones que cruzan alianzas internacionales y necesidades locales para dar formas a las relaciones entre los actores a nivel nacional:

De una parte, la UIAW se ubica como una institución con fuertes vínculos internacionales a propósito de las reivindicaciones por una epistemología propia y contra-hegemónica, su trabajo político institucional a nivel regional la ha consolidado como una experiencia ejemplar en educación superior indígena / intercultural con amplio apoyo de parte de un circuito particular de organizaciones e intelectuales que han venido pensando el problema de la interculturalidad. No obstante, a nivel local, a pesar de las esperanzas iniciales, la UIAW pierde credibilidad y legitimidad entre los impactos del proceso de evaluación adelantado por el Estado, los problemas económicos que han signado su devenir, y las propias falencias organizativas, administrativas y académicas de la UIAW como institución para la formación superior. La pérdida de credibilidad a la que hago referencia se refleja tanto en las opiniones de estudiantes y docentes registradas en encuestas y entrevistas, como en la evidente deserción de estudiantes y en la falta de movilización real (contenciosa y no contenciosa, más allá del comunicado diplomático), de parte de las organizaciones locales de base y las organizaciones regionales-nacionales. El logro del Movimiento Indígena de antaño, posicionar temas de tan alto alcance como interculturalidad y plurinacionalidad en la arena pública, se quedó en la arenga política dejando de lado el proyecto epistémico alternativo y emancipatorio, sobre todo en el ámbito de la educación. 
De otra parte, el gobierno de Correa se ubica como un nuevo proyecto de Estado en refortalecimiento a costa de la organización social. Si bien la aceptación del accionar del gobierno es amplia y se ha corroborado en dos faenas electorales $\mathrm{y}$, al igual que la UIAW, a nivel internacional es reconocido como uno de los proyectos progresistas ejemplares de la región; es preciso afirmar que su proceso efectivo de consolidación solo ha sido posible gracias al cierre de cualquier tipo de escenario que implique la negociación del devenir socio-político nacional con las organizaciones sociales, es decir, el refortalecimiento del Estado ecuatoriano solo ha sido posible tras el cierre de los canales de negociación del poder con las organizaciones sociales, entre ellas, las organizaciones indígenas, situación que implica deslegitimar y negar al sujeto “organización indígena” como sujeto político. En este marco, la UIAW se coloca bajo la lupa del Estado en el contexto de la reforma de la Educación Superior y, al igual que con el Movimiento Indígena, sus discursos y sus posibilidades prácticas se llevan a la palestra para ser juzgados en relación a su posición frente al gobierno.

Lo real y no lo potencial, escenario sobre el cual se elabora el presente trabajo investigativo, permite señalar que esta configuración particular del campo de batalla por el proyecto de educación superior intercultural y por la interculturalidad misma, hace imposible el cumplimiento de la promesa de interculturalidad como una universalidad dialogada. La confianza, la solidaridad y la voluntad necesarias para emprender procesos de diálogo y consenso entre paradigmas culturales diferentes que repercutan en la negociación del bienestar común y, por ende, en la definición de estrategias económicas, políticas y sociales en pro del reconocimiento de la diferencia y la redistribución de la riqueza y el poder a nivel nacional, son condiciones hoy imposibilitadas tanto por las agendas del actual proyecto de gobierno como por las tareas aún pendientes del actual Movimiento Indígena en transformación.

Así, mientras que se erige un gobierno que reproduce la estrategia desarrollista de la Modernidad, instituye como política el multiculturalismo neoliberal/posneoliberal y acaba con las posibilidades de incidencia real de los sujetos colectivos de derecho instituyendo al ciudadano individual como único sujeto político legítimo (suponiendo que este realmente tiene alguna participación en lo político más allá del voto y el acceso a servicios); a la par, se evidencia cómo las banderas políticas del Movimiento se quedan sin acompañamiento operativo ante los retos que implica llegar a la arena pública. Las prácticas de la UIAW también reflejan estas falencias pues no evidencian capacidades técnico-administrativas que les permitan funcionar como institución moderna (o, como alternativa, tampoco muestran los resultados de la construcción de alguna estrategia operativa sólida que permita hacer frente y oposición real al proyecto de evaluación y construcción de criterios adelantados por el CEAACES), no registran un acompañamiento del Movimiento Indígena que repercuta en acciones conjuntas, y ha descuidado su relación directa con las bases.

En este marco, es de mi mayor preocupación, la evidencia de un 
nuevo proceso de cierre frente a las posibilidades de acción de la sociedad civil organizada, para este caso en particular, el cierre de las posibilidades de acción de las organizaciones indígenas y, por ende, la institucionalización de la exclusión de los sujetos colectivos indígenas en la toma de decisiones que definen el presente y el futuro nacional. Si bien es imposible olvidar el proceso histórico que hace emerger tanto la necesidad de los procesos de fortalecimiento de la estructura estatal como la necesidad de realizar una reforma al sistema de educación superior nacional y también es difícil negar la ampliación de la inversión social de parte del gobierno e incluso el paso que se da al implementar sistemas de cuotas para indígenas en los cargos públicos; es imperativo recordar que i) acceso a servicios no implica ni participación ni incidencia y que ii) la política de la presencia que se instituye a través de acciones de afirmación positiva, no garantiza la inclusión y trámite efectivo de las demandas de las diversidades culturales y étnicas en la creación, ejecución y evaluación de la política pública, por ende, en la determinación a propósito de un modelo de educación superior adecuada.

En esta instancia, también es importante considerar que tanto el proyecto de la UIAW como el proyecto del actual gobierno son proyectos jóvenes y en marcha; no obstante, esta no puede ser la excusa para evitar el ir evaluando los procesos de forma crítica y con el fin de corregir errores y re-dirigir acciones.

Hoy, después de trabajar algún tiempo observando las organizaciones sociales indígenas en Ecuador tras la búsqueda de ubicar experiencias prácticas y teóricas que posibiliten alternativas en educación, creo con certeza que mientras que no se den transformaciones radicales y con capacidad de influencia y contagio a nivel nacional y regional frente a las formas de producir y re-producir la vida y, por ende, frente a las formas de gobierno y administración de la población y el territorio (palabras más palabras menos, mientras permanezcan el capitalismo y el Estado liberal como los marcos que limitan el ser/estar de las poblaciones en contextos específicos); solo es en las negociaciones justas y equitativas, tanto con el mercado como con el Estado, que se puede garantizar la resistencia como forma de sobrevivencia digna, en consecuencia, solo desde allí la resistencia se puede hacer hegemonía. El quehacer político de hoy entonces es garantizar las condiciones necesarias para establecer los campos (justos y equitativos) de negociación y, de manera paralela, prepararse (en los frentes políticos pero también técnicos, académicos y operativos) para la contienda. 


\section{Notas}

${ }^{1}$ El presente artículo hace parte de las reflexiones en construcción a propósito de la investigación "La interculturalidad imposible. Relaciones entre el proyecto educativo indígena y el Estado ecuatoriano. El caso de la Universidad Intercultural Amawtay Wasi”, trabajo de tesis realizado para obtener el título de Maestría en Ciencias Sociales con mención en Sociología de la FLACSO-Ecuador. La investigación es resultado de una estrategia metodológica que acompaña la revisión de literatura en el campo de análisis, con la lectura de la legislación producida al respecto, el acercamiento a través de conversaciones informales, entrevistas y encuestas a los actores participes en este proceso (organizaciones sociales indígenas, intelectuales indígenas, expertos en el tema, miembros y funcionarios de instituciones de Estado clave -SENESCYT y CEAACES-, y dirigentes, facilitadores y estudiantes de la UIAW) y una participación cercana en el devenir institucional, administrativo, académico y político de la UIAW desde el año 2008, año en el que inicie el trabajo de campo de la tesis de pregrado “Alternativas Curriculares en Educación superior: Derroteros Posibles hacia la Decolonialidad. La Experiencia de la Universidad Intercultural Amawtay Wasi (Quito, Ecuador)” (Bustamante y Vargas 2010).

${ }^{2}$ Empleo la categoría política dual propuesta por Arato y Cohen (1999, 2000) como un marco de interpretación que permite entender a la sociedad civil como un escenario abierto e internamente heterogéneo, inconcluso y contradictorio e históricamente contingente. Esta perspectiva permite entender los movimientos sociales como actores políticos que actúan entre la movilización de base (en pro de la visibilización y la identidad como cohesión en donde es posible la resignificación del pasado y la reinvención de la tradición) y la institucionalización (como forma de influir y transformar el sistema político y económico).

${ }^{3}$ Los trabajos realizados por el Grupo de Estudios Modernidad-Colonialidad han construido tres categorías que dan razón de los conceptos específicos que analizan y explican la experiencia de la colonialidad en América Latina; a saber, la Colonialidad del Ser, equivalente a la invisibilización y deshumanización; la Colonialidad del Saber, entendida como homogenización del pensamiento y universalización de la razón instrumental occidental; y, finalmente, la Colonialidad del Poder, que enmarca el ejercicio del poder disciplinario por parte del colonizador basado en el concepto de raza. Para ampliar esta referencia véase: Escobar, Arturo (2003)

4 "La completitud -la idea de que la cultura o la propia política proporciona respuestas a todas las preguntas- es a menudo el punto de partida de algunos movimientos. La traducción avanza en la medida en que la completitud va dando lugar a la conciencia de incompletitud cultural, es decir, la idea de que existen deficiencias en la cultura o en la propia política y que éstas pueden ser parcialmente superadas con las contribuciones de otras culturas o políticas” (Santos 2012).

${ }^{5}$ Los términos chakra, y aja, de las lenguas kichwa y shuar respectivamente, son equivalentes a huerta, lugar de trabajo agrícola, tierra cultivable. La UIAW emplea estos dos términos, dependiendo del territorio en donde se imparten las clases, como metáforas para representar estas "sedes" o "extensiones" como territorios de trabajo vinculados a las comunidades en donde se cultiva y se cosecha conocimiento.

${ }^{6} \mathrm{~A}$ propósito del significado de la categoría "guerra de posiciones” en Gramsci, el 
filósofo italiano Giuseppe Prestipino afirma: La guerra de posiciones consiste en efecto en un "recíproco asedio". A veces la parte conservadora advierte la necesidad de promover mutaciones y reformas, mientras que la fuerza revolucionaria puede promover la gradual conquista de posiciones hegemónicas, aunque sean parciales, aún antes de hacerse Estado. En una acabada dialéctica "revolución-restauración" considerada en las dos salidas posibles, no solo al viejo régimen se le plantea la tarea, con fines restauracionistas precisamente, de aprehender en sí también algunos intentos programáticos de la revolución; también lo nuevo operaría objetivamente de esa manera, aunque en la dirección contraria [...]De ahí se deduce que el paso a la guerra de posiciones se produce no cuando existe "mayor autonomía de la sociedad civil", si no cuando aparece un mayor equilibrio dialéctico entre aparato estatal y sociedad civil (Prestipino, 2005: 113).

${ }^{7}$ El miércoles 13 de mayo de 2009 el nuevo presidente de Ecuador, se comprometía, en el funeral de la líder indígena Tránsito Amaguaña, a acabar con la injusticia social y la pobreza cuyas principales víctimas han sido los pueblos y nacionalidades indígenas. En palabras de Correa: "Delante de ella me comprometo en nombre del gobierno nacional y de la Revolución Ciudadana a radicalizarnos y a luchar más fuerte, compañeros, para acabar con este estado de injusticia y desigualdad, donde una de las mayores víctimas han sido nuestros pueblos ancestrales"

8 “La Revolución está en marcha” es uno de los eslóganes institucionales del primer período de gobierno de Correa. (Eslóganes: del inglés slogan y este del gaélico escocés sluagh-ghairm: grito de guerra).

${ }^{9}$ LaClau y Mouffe (1987) en su amplio trabajo en torno a la construcción de la hegemonía en las sociedades contemporáneas, dan cuenta de un pluralismo antagónico imperante en la sociedad como potencial para la consolidación de una democracia radical. Al hablar de las dificultades de la clase obrera para definirse como una totalidad constituida, con límites y parámetros definitivos, señalan cómo el "positivismo ingenuo del socialismo científico” ha caído en una trampa racionalista que niega la dispersión y fragmentación propia de las diversas posicionalidades de los agentes sociales. Para los autores el problema radica en la imposibilidad de la sutura de lo social, en la propia sobredeteminación de la identidad: “Esta era la lógica de la sobredeterminación. Para ella el sentido de toda identidad está sobredeterminado en la medida en que toda literalidad aparece constitutivamente subvertida y desbordada; es decir, en la medida en que, lejos de darse una totalización esencialista o una separación no menos esencialista entre objetos, hay una presencia de unos objetos en otros que impide fijar su identidad. Los objetos aparecen articulados, no en tanto que se engarzan como las piezas de un mecanismo de relojería, sino en la medida en que la presencia de unos en otros hace imposible suturar la identidad de ninguno de ellos” (LaClau y Mouffe, 1987: 175-176).

${ }^{10}$ En el mes de noviembre del año 2009, el asambleísta por la provincia de Chimborazo, Gerónimo Yantalema, ante la convocatoria de la Asamblea General de la Nación, presenta una propuesta para la elaboración de la LOES (Aportes para la propuesta de Ley, 2009) (LOES. Octubre, 2010) La propuesta, además de señalar la necesidad de incluir categorías propias de la racionalidad Abya-Yala, recuperar el sistema de valores y conocimientos indígenas, reconocer la importancia de las autoridades y sabedores tradicionales y la construcción de criterios propios de evaluación intercultural, insiste en la obligación del Estado de financiar la Universidad Intercultural y sugiere cambiar el carácter de la UIAW de particular-privado a comunitario con financiamiento estatal 
(Aportes para la propuesta de Ley, 2009). No obstante, la propuesta no fue tomada en cuenta. Como bien lo narra Sarango (Boletín Digital, Septiembre de 2011) "Convencidos que la Asamblea Nacional escucharía nuestros criterios y aportes para formular la nueva Ley Orgánica de Educación superior (LOES), conforme nos dijeron, participamos entusiastas fundamentando la necesidad de que la nueva ley establezca la responsabilidad que tiene el estado ecuatoriano para con la educación superior intercultural conforme al Convenio No. 169 de la OIT, y reconozca finalmente un nuevo tipo de universidad, la universidad comunitaria. Nuestra propuesta aunque con otro nombre llegó hasta el segundo debate, más el veto presencial eliminó totalmente nuestra aspiración”. 


\section{Bibliografía}

Arato, Andrew (1999), "Surgimiento, ocaso y reconstrucción del concepto de sociedad civil y lineamientos para la investigación futura”, en: Alberto J. Olvera (Coord.), La sociedad civil de la teoría a la realidad, El Colegio de México, México, pp. 113-132.

Arato, Andrew y Jean Cohen (2000), Sociedad civil y teoría política, Fondo de Cultura Económica, México.

Bustamante Leidy y Paola Vargas (2010), Alternativas Curriculares en Educación superior: Derroteros posibles hacia la decolonialidad. La experiencia de la Universidad Intercultural Amawtay Wasi (Quito, Ecuador), Tesis de Licenciatura en Educación Básica con énfasis en Ciencias Sociales, Universidad Distrital Francisco José de Caldas. Bogotá.

Dávalos, Pablo (2005), “Movimientos Indígenas en América Latina. El Derecho a la palabra”, en: Pueblos Indígenas, Estado y Democracia. Memorias del encuentro del Grupo de Trabajo de CLACSO Movimientos Indígenas en América Latina, Quito, 2004. Taller de Gráfica y Servicios, Argentina, pp. 17-33.

Ídem (2010), La democracia disciplinaria. El proyecto posneoliberal para América Latina, CODEU-PUCE, Quito.

Ídem (s/f. s/r), Alianza País: Réquiem por un sueño, Quito.

Escobar, Arturo (2003), “Mundos y Conocimientos de Otro Modo. El Programa de Investigación Modernidad/Colonialidad”, en: Revista Tabula Rasa, Universidad Colegio Mayor de Cundinamarca, Bogotá, pp. 51-86.

LaClau, Ernesto y Chantal Mouffe (1987), Hegemonía y Estrategia Socialista. Hacia una radicalización de la democracia, Siglo XXI Editores, Madrid.

Ley Orgánica de Educación superior (Octubre 2010), Presidencia de la República del Ecuador. Registro Oficial N²98 de 12 de octubre de 2010.

Macas, Luis (2005), “La necesidad política de una reconstrucción epistémica de los saberes ancestrales”, en: Pueblos Indígenas, Estado y Democracia. Memorias del encuentro del Grupo de Trabajo de CLACSO Movimientos Indígenas en América Latina, Quito, 2004. Taller de Gráfica y Servicios, Argentina, pp. 35-42.

Mato, Daniel (2008), “Diversidad cultural e interculturalidad en Educación superior. Problemas, retos y oportunidades en América Latina”. en: Daniel Mato (Coord.), Diversidad cultural e interculturalidad en Educación superior. Experiencias en América Latina, Instituto Internacional de la UNESCO para la Educación superior en América Latina y el 
Caribe, Caracas, pp. 21-79.

Prestipino, Giuseppe (2005), "Dialéctica en Gramsci", en: Herramienta. Revista de debate y Crítica Marxista, № 29 (jun.-2005), Buenos Aires, pp. 103-123.

Reglamento de Régimen Académico (2013), Consejo de Educación superior. República de Ecuador. Disponible en: http://www.ces.gob.ec/regimenacademico/borrador-integrado-del-reglamento-regimen-academico

Santos, Boaventura de Sousa (1998), De la mano de Alicia. Lo social y lo político en la postmodernidad, Siglo del Hombre Editores. Facultad de Derecho Universidad de los Andes, Bogotá.

Ídem (2007), “La universidad en el siglo XXI. Para una reforma democrática y emancipadora de la universidad”, en: Revista Umbrales $\mathrm{N}^{\circ} 15$. Universidad Mayor de San Andrés, La Paz, pp. 13-70.

Ídem (2012), De las dualidades a las ecologías. Serie: Cuadernos de Trabajo $N^{\circ} 18$, Red Boliviana de Mujeres Transformando la Economía REMTE. La Paz.

Sarango, L. Fernando (2008), “La experiencia de la Universidad Intercultural de las Nacionalidades y Pueblos Indígenas Amawtay Wasi”, en: Daniel Mato (Coord.), Diversidad cultural e interculturalidad en Educación superior. Experiencias en América Latina, Instituto Internacional de la UNESCO para la Educación superior en América Latina y el Caribe, Caracas, pp. 265-275.

Ídem (2009), “Triunfo histórico, diálogo y radicalización de la revolución”, en: Boletín Digital de la Universidad Intercultural Amawtay Wasi. № 12. Mayo de 2009.

Ídem (2010). “¿Por qué la Universidad Comunitaria no cabe en la Revolución Ciudadana?”, en: Boletín Digital de la Universidad Intercultural Amawtay Wasi, $N^{\circ}$ 15, Agosto de 2010.

Ídem (2011), “Universidad Comunitaria Intercultural Amawtay Wasi. Siete años de lucha, siete años de esperanza. El primer Pachakutik”, en: Boletín Digital de la Universidad Intercultural Amawtay Wasi, $\mathrm{N}^{\circ} 16$. Septiembre de 2011.

Tünnerman B., Carlos (2001), La educación superior según el informe del grupo de trabajo del Banco Mundial y la UNESCO, Managua.

Universidad Intercultural Amawtay Wasi (2004), Aprender en la sabiduría y el buen vivir, Abya-Yala, Quito. 
Polis, Revista Latinoamericana, Volumen 13, $N^{\circ}$ 38, 2014

\section{Entrevistas citadas}

Luis Macas (Entrevista. Julio de 2013), Kichwa-saraguro. Ex-Diputado Nacional. Ex-Ministro de Agricultura. Ex-Presidente de la CONAIE. Miembro del equipo fundador del proyecto educación intercultural bilingüe EIB por la CONAIE. Miembro del equipo fundador de la UIAW.

Gerardo Simbaña (Entrevista. Junio de 2013), Kichwa-kitu kara. Coordinador Académico de la UIAW.

Luis Andrango (Entrevista. Abril de 2013), Kichwa. Ex presidente de la FENOCIN.

Recibido: 26.05.2014

Aceptado: 15.07.2014 